\title{
The effect of boron on the abrasive wear behavior of austenitic Fe- base hardfacing alloys
}

Ki nam Kim, Myung Chul Park Gyeong Su Shin and Seon Jin Kim ${ }^{\mathrm{a}}$

Division of materials science and engineering, Hanyang university, Seoul, 133-791, Korea

\begin{abstract}
The effect of boron on the abrasive wear behavior of the austenitic Fe-Cr-C-Si-B hardfacing alloys was investigated with varying boron concentration. It was found that the abrasive wear resistance of the hardfacing alloys increased up to $50 \%$ compared to that of boron free alloys with increasing boron concentration. The mechanism of the abrasive wear resistance changed at $0.6 \mathrm{wt} \%$ boron. Below $0.6 \mathrm{wt} \%$ boron concentration, the abrasive wear resistance was improved almost linearly and strain-induced martensitic transformation was considered as the controlling factor for improving the resistance. Above $0.6 \mathrm{wt} \%$ boron, it was observed that the primary borides started to precipitate. Further increase in boron concentration was not able to enhance the resistance due to the negligible change of primary borides' size and volume fraction. With these results, it was concluded that two different effects of boron on the wear resistance of the austenitic Fe-Cr-C-Si-B hardfacing alloys existed depending on the boron concentration.
\end{abstract}

\section{Introduction}

The hardfacing process is an effective tool for const reduction and maximizing the wear resistance and thus increasing the life of machinery components by overcoming the severe destructive wear conditions. For resisting the severe wear conditions, Fe-based high $\mathrm{Cr}$-C alloys have been mainly used owing to their good abrasive wear resistance. The excellent abrasive wear resistance of the $\mathrm{Cr}-\mathrm{C}$ alloys are traditionally attributed to formation of hard chromium-carbide [1]. However, Chatterjee and Pal [3] reported that the abrasive wear resistance may not be further improved even if high volume fraction of chromium carbides were present,(over $35 \mathrm{vol} . \%$ ). In this respect, a strain-induced martensitic transformation and primary borides can be an attractive solution to improve the abrasive wear resistance further.

With addition of boron in Fe-based austenitic alloy, it is expected that the austenite grain size will decrease and that grain size reduction will then expedite the transformation of the austenite into martensite [2]. In addition to the grain size refinement effect, primary borides can also be helpful to improve the abrasive wear resistance due to the high potential of excellent wear and corrosion resistance and the high hardness of the primary borides [3]. Therefore, increasing boron concentration should result in further improvement of the abrasive wear resistance in addition to the effect of already-existing chromium carbides. In this paper, the effect of boron on the abrasive wear behavior in terms of a strain-induced martensitic transformation and primary borides formation was investigated

\section{Experimental procedure}

Austenitic Fe-20Cr-2.4C-1Si- $x \mathrm{~B}$ alloys with varying boron concentration from 0.0 to $2.6 \mathrm{wt} \%$ were prepared by induction melting under an argon atmosphere and those alloys were machined by wire cutting according to ASTM A-36 electrode specimen and the abrasive wear tests were performed. The chemical composition of the alloy was analyzed using an optical emission spectrometer and the chemical composition is summarized in Table 1. The surfaces of specimens was polished to a roughness value of $\boldsymbol{R}_{a}<0.02 \mu \mathrm{m}$ by grinding on 2000 grit $\mathrm{SiC}$ abrasive paper. The abrasive wear tests were performed in accordance with ASTM G-65. The type of abrasive particles were AFS 50/70 Ottawa test sand and those particles' diameter was 212 300 $\mu$ m.

The followings were test conditions; load $130 \mathrm{~N}$, sand flow rate $25 \mathrm{~g} / \mathrm{min}$, wheel rotation speed $200 \mathrm{rpm}$, wheel diameter $228.6 \mathrm{~mm}$ and the tests were terminated after 6000cycles rotations. After the tests were performed, optical microscopy was carried out. X-ray diffractometer was used to identify the crystalline phases.

\footnotetext{
a e-mail: alloylab@hanyang .ac.kr
}

This is an Open Access article distributed under the terms of the Creative Commons Attribution-Noncommercial License (http://creativecommons.org/licenses/by-nc/3.0/), which permits unrestricted use, distribution, and reproduction in any noncommercial medium, provided the original work is properly cited. 


\section{Results and discussion}

As shown in Fig. 1(a) and (b), the weight losses of austenitic alloys decreased as increasing boron concentration up to $0.6 \mathrm{wt} \%$. Below $0.6 \mathrm{wt} \%$ boron concentration, the abrasive wear resistance increased up to about $50 \%$ with increasing the boron concentration compared to that of $\mathrm{Fe}-20 \mathrm{Cr}-2.4 \mathrm{C}-1.0 \mathrm{Si}$ boron free alloy. In detail, the alloys containing boron up to $0.6 \mathrm{wt} \%$ showed the abrasive wear resistance of $\sim 31 \%$ and this effective increasing of wear resistance can be explained by grain size reduction.
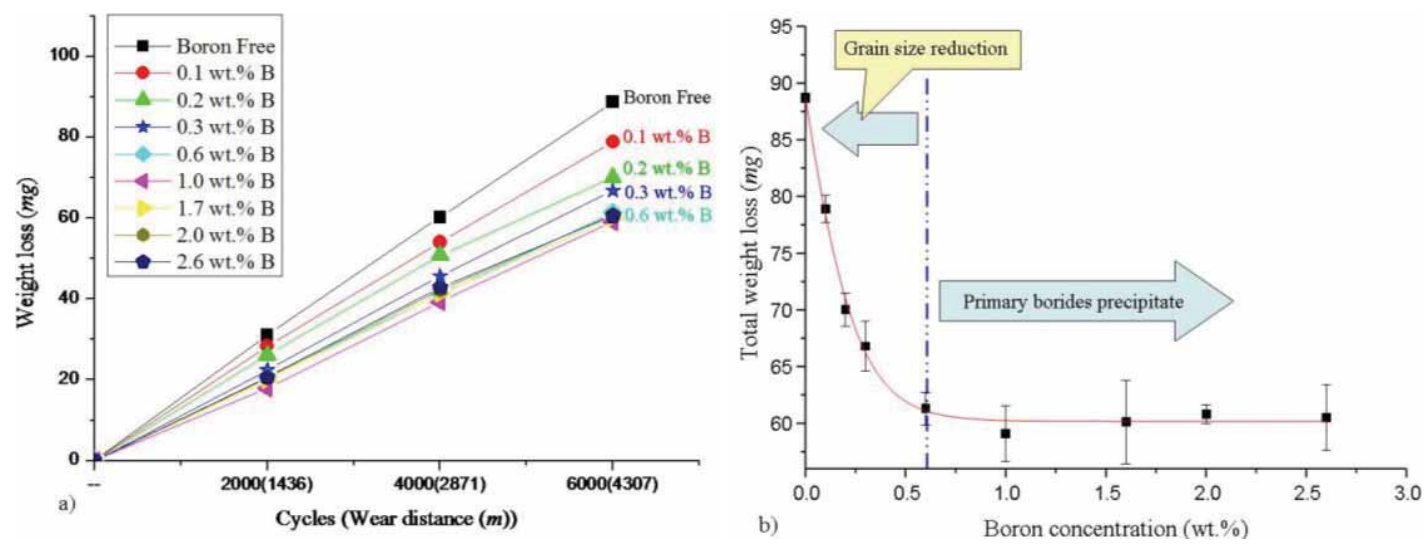

Fig. 1. (a) The weight losses of boron free and boron-added alloys as a function of wear distance after 2000, 4000 and 6000 cycles of wear test and (b) total wear losses as a function of boron concentration

As shown in the metallographic of $\mathrm{Fe}-20 \mathrm{Cr}-2.4 \mathrm{C}-1.0 \mathrm{Si}-\mathrm{xB}$ with varying boron concentration from 0.0 to 0.3 $w t \%$ (see Fig. 2), it is found that the mean austenite grain size decreased as increasing boron concentration. Fig. 5 shows the estimated grain size as a function of boron content, confirming the dramatic reduction in grain size with increasing boron content. This grain size reduction should lead to hardening of austenite matrix in accordance with Hall-Petch equation and that hardened matrix could be one of the factors to resist abrasive particles and enhance the abrasive wear resistance.

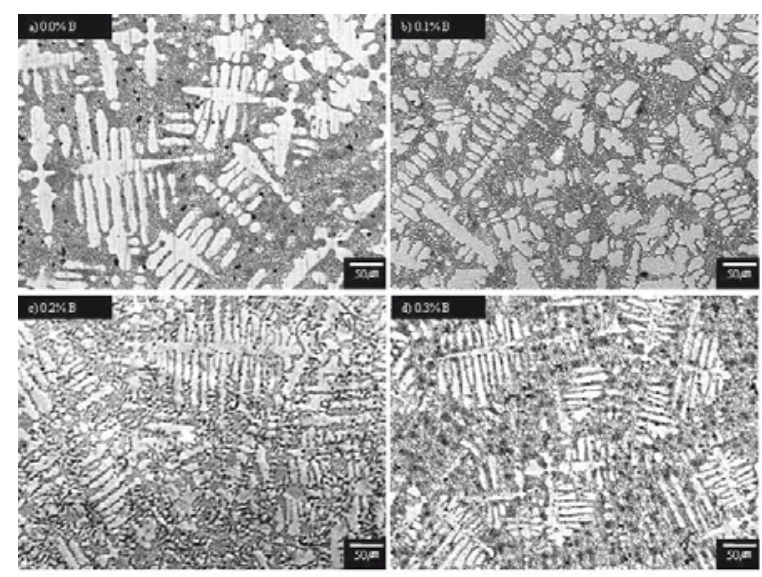

Fig. 2. Metallographic of Fe-20Cr-2.4C-1.0Si including (a) $0.0 w t \% \mathrm{~B}$, (b) $0.1 w t \% \mathrm{~B}$, (c) $0.2 w t . \% \mathrm{~B}$ and (d) $0.3 w t . \% \mathrm{~B}$

In addition to mean grain size reduction effect mentioned above, the strain-induced martensitic transformation can be inferred from the grain size reduction. According to the previous report by De et al. [3] who treated the effect of grain size on the strain-induced martensitic transformation, the phase transformation can be assisted by decreasing the grain size. X-ray diffraction data of worn surfaces are presented in Fig. 3 which indeed verifies that the relative fraction of martensite markedly increased at $0.3 \mathrm{wt} \%$ and $0.6 \mathrm{wt} \%$ compared to $0.0 \mathrm{wt} \%$ boron as the relative intensities of the retained austenite and martensite were compared. Fig. 4 shows the hardness profile of worn surfaces and it proves that the worn surfaces of $0.0,0.3$ and $0.6 w t \% \mathrm{~B}$ were hardened by strain- 
induced martensitic transformation. Thus, it is concluded that the transformed martensite during the abrasive wear test could resist the plastic deformation by abrasive particles due to martensite's high hardness and resulted in improvement of the abrasive wear resistance. There was a previous report on improvement of the abrasive wear resistance through strain-induced martensitic transformation [2]. Thus, the abrasive wear resistance, in the range of 1.0 to $2.6 \mathrm{wt}$.\% boron concentration, did not improved as increasing boron concentration and saturation of weight losses was recorded.

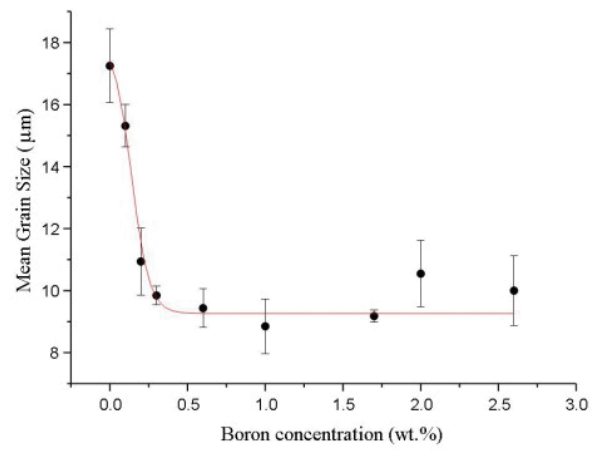

Fig. 3. Mean grain size reduction as a function of a boron concentration

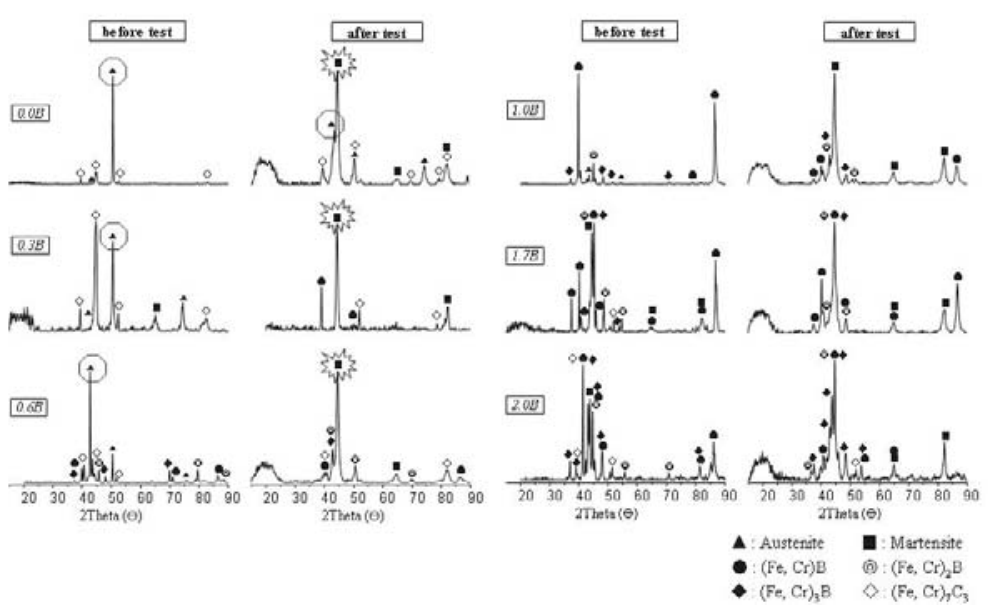

Fig. 4. X-ray diffraction data of Fe-20Cr-2.4C-1.0Si including boron concentration up to $2.0 w t . \%$ after abrasion test

\section{Conclusions}

The abrasive wear resistance of austenitic Fe-20Cr-2.4C-1.0Si-xB with varying boron concentration improved as increasing boron concentration up to $0.6 \mathrm{wt} . \%$. Over $0.6 \mathrm{wt} . \%$ boron concentration, the abrasive wear resistance was almost saturated. The mechanism of the abrasive wear resistance changed as function of boron concentration and main conclusions are as follows:

1. In a hardfacing alloy of Fe-20Cr-2.4C-1.0Si, the strain-induced martensitic transformation improved the abrasive wear resistance and the martensitic transformation was accelerated through grain size reduction by boron addition below $0.6 \mathrm{wt} \%$.

2. At 0.6 wt. $\%$ boron concentration, the primary borides were started to precipitate and these precipitates resulted in an improvement of the abrasive wear resistance.

3. Further increasing of boron concentration above $1.0 \mathrm{wt} \%$, the resistance of abrasive wear was almost saturated due to the negligible change of primary borides' size and volume fraction.

\section{References}

[1] I.R. Sare, Abrasion resistance and fracture toughness of white cast irons. Met. Technol. 1979; 6: $412-419$.

[2] S. Chatterjee, T.K Pal. Wear behavior of hardfacing deposits on cast iron. Wear 2003; 255: 417-425.

[3] Amar K. De, David C. Murdock, Martin C. Quantitative measurement of deformation-induced martensite in 304 stainless steel by X-ray diffraction. Scripta Materialia 2004; 50: 1445-1449 